\title{
Application of SeDeM Expert System in the development of novel directly compressible co-processed excipients via co-processing
}

Ilyasu Salim $^{1 *}$ (D, Adeniji Kehinde Olowosulu², Abdulrahman Abdulsamad², Mahmud Sani Gwarzo', Garba Mohammed Khalid ${ }^{3}$, Naimatu Tijjani Ahmad ${ }^{2}$, Florence Egbomonjiade Eichie ${ }^{4}$ and Fatima Shuaibu Kurfi ${ }^{5}$

\begin{abstract}
Background: Computer-aided formulation design is gaining fantastic attention in chemical engineering of high functionality pharmaceutical materials for dosage form manufacture. To accelerate development of novel formulations in a quality-by-design perspective, SeDeM Expert System preformulation algorithm was developed as a tool for the design of solid drug delivery systems and for prediction of direct compression manufacturability of solid formulations. This research aims to integrate SeDeM Expert System into particle engineering design space of co-processing of solid excipients to develop novel composites with optimum direct compression propensity, using corn starch and microcrystalline cellulose powders as model primary excipients.

Result: The data and information generated from the expert system have elucidated the bulk-level characteristics of the primary excipients, enabled computation of the optimum co-processing ratio of the ingredients, and validated the impact of co-processing on material functionality. The experimental flowability (7.78 \pm 0.17$)$, compressibility functions (5.16 \pm 0.14$)$, parameter profile (0.92), and parametric profile index (6.72 \pm 0.27$)$ of the engineered composites, were within the acceptable thresholds. With a reliability constant of 0.961 , the net direct compression propensity of the composites expressed as Good Compression Index (6.46 \pm 0.26$)$ was superior to that of the primary excipients, but comparable to reference co-processed materials, StarLac ${ }^{\circledast}(6.44 \pm 0.14)$ and MicroceLac ${ }^{\oplus} 100(6.58 \pm 0.03)$.

\footnotetext{
* Correspondence: silyasu.pht@buk.edu.ng

'Department of Pharmaceutics and Pharmaceutical Technology, College of Natural and Pharmaceutical Sciences, Bayero University, PMB 3011, Kano,

Nigeria

Full list of author information is available at the end of the article
}

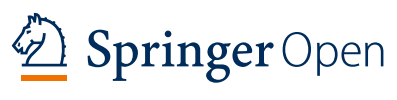

(c) The Author(s). 2021 Open Access This article is licensed under a Creative Commons Attribution 4.0 International License which permits use, sharing, adaptation, distribution and reproduction in any medium or format, as long as you give appropriate credit to the original author(s) and the source, provide a link to the Creative Commons licence, and indicate if changes were made. The images or other third party material in this article are included in the article's Creative Commons licence, unless indicated otherwise in a credit line to the material. If material is not included in the article's Creative Commons licence and your intended use is not permitted by statutory regulation or exceeds the permitted use, you will need to obtain permission directly from the copyright holder. To view a copy of this licence, visit http://creativecommons.org/licenses/by/4.0/. 


\begin{abstract}
(Continued from previous page)
Conclusion: Application of SeDeM Expert System in particle engineering via co-processing has provided an accelerated upstream proactive mechanism for designing directly compressible co-processed excipients in a qualityby-design fashion. A four-stage systematic methodology of co-processing of solid excipients was postulated. Stage I entails the characterization of CMAs of both defective and corrective excipients, and elucidation of their physicomechanical limitations using SeDeM diagrams. Stage // involves computation of loading capacity of the corrective excipient using dilution potential equation. Stage III entails the selection of co-processing technique based on desired Critical Material Attributes as revealed by the information obtained from Stage I. Stage IV evaluates the impact of co-processing by monitoring the critical behavior of the engineered composites with a decision on either to accept or reject the product.
\end{abstract}

Keywords: Particle engineering, Co-processing, Computer-aided formulation design, SeDeM Expert System, Direct compression, Quality-by-design, Starch, Microcrystalline cellulose

\section{Background}

The quest to develop novel excipients is increasing partly due to the inefficiency of existing pharmaceutical materials to satisfactorily address the critical functionality requirements of modern manufacturing machines and/or peculiarities of advanced drug delivery systems to obtain products with acceptable target quality product profiles (QTPPs) [1, 2]. Moreover, the vision of the pharmaceutical industry in adoption of the principles of lean manufacturing geared towards improving production efficiency, reduction of time to market of formulated products, and ensuring sustainable and affordable supply of high-quality medicines has dramatically changed the way pharmaceutical products are designed, developed, and manufactured [3-5]. This is very true when direct compression (DC) method of tablet production is considered. DC is an economic tablet manufacturing process that allows tableting via fewer unit operations, thus devoid of complex process validation procedures typical in tableting by roller compaction or wet granulation [6, 7]. However, because DC has stringent requirements for materials with efficient physicomechanical functionality, significant number of single-component excipients (SCEs) and active pharmaceutical ingredients have inherent rheological deficiencies limiting optimal utilization of direct compression for tableting [8, 9]. Consequently, to produce tablets of acceptable QTPPs, the utilization of direct compression technology is limited to a fraction of pharmaceutical excipients [9-11].

To fully maximize the manufacturing potentials of tableting by direct compression, novel high functionality excipients are needed to mitigate the short falls of existing SCEs [12]. Unfortunately, because novel excipients are considered by the regulatory bodies as new chemical entities (NCEs), and that there is no independent regulatory route for their development, similar level of scrutiny as novel drug molecules for safety evaluation in humans applies [1]. Given the complex scientific, economic, and regulatory uncertainties surrounding development of
NCEs [13], this route is commercially non-rewarding for excipient development.

A more plausible pathway to develop new tableting excipients involves functional modification of existing SCEs with established regulatory safety profiles, tagged Generally Regarded as Safe (GRAS) [14]. Particle engineering technologies such as co-processing are explored to create novel co-processed excipients, a combination of two or more GRAS listed excipients, to create novel functionality for expanded application in tablet manufacture $[15,16]$. Consequently, development of co-processed excipients enjoys a regulatory leverage over synthesis of entirely new chemical entities. Co-processed excipients have been reported to have superior advantage in terms of critical tableting properties than the corresponding SCEs $[11,16,17]$. Despite their availability, co-processed excipients are still scanty, and because they exist in a fixed combination, their versatility in direct compression is limited $[18,19]$. Consequently, there is need to develop newer tableting materials to bridge this gap.

Given the urgent need to develop cost-realistic high functionality novel co-processed excipients with proven superiority over traditional excipients pursuant to the objectives of the International Council for Harmonization of technical requirement for registration of medicines for human use (ICH), there is need for process engineers and formulation scientists to deploy eresources in accelerating research and development and reduction of time to market while concurrently striking a balance between quality and regulatory requirement. Fortunately, as a result of digital revolution, computeraided formulation development tools are gaining fantastic attention in chemical engineering of high-quality pharmaceutical materials for dosage form manufacture [20-22]. Formulation development tools are sets of edevelopment algorithms based on special or conventional computer programming languages that assist formulators to design products in a simple, reliable, and systematic manner [21-24]. 
To accelerate solid formulations development in a Quality-by-Design (QbD) perspective, SeDeM Expert System was invented to serve as a preformulation algorithm for prediction of direct compression suitability of powder systems based on computation of critical direct compression variables [24-26]. The expert system was equally applied in monitoring the critical behavior and percolation threshold of powder systems [27], and as optimization tool has aided in the quantitative estimation of optimum amounts of high functionality excipients required to fabricate poorly compressible active drugs into tablets by direct compression technology [28]. Because co-processing requires critical understanding of the complex interactions of solid bulk-level properties and how their physical modifications affect tableting properties [29], it is inferential that integration of SeDeM Expert System could be of significant merit in product design and optimization of novel co-processed excipients. Therefore, the goal of this research was aimed at accelerating development and optimization of novel co-processed excipients by the application of SeDeM Expert System in co-processing technology. For the first time, the suitability of the expert system for systematic development of novel co-processed excipient using corn starch (a poorly compactible) and microcrystalline cellulose (a highly compressible) powders as model primary excipients powders was investigated.

\section{Methods}

\section{Materials}

A predominantly plastic deforming excipient-microcrystalline cellulose powder (Avicel PH101, FMC Corporation, UK) and a fairly elastic deforming excipientcorn starch powder (CDH Chemicals, India), were used as model primary excipients. Polyvinylpyrrolidone (CDH Chemicals, India) was used as a binding agent during co-dispersion. Magnesium stearate, colloidal silicon dioxide, talc (Merck, Sigma-Aldrich) functioned as lubricating and flow enhancing agents for compaction of corn starch only. Two commercially available directly compressible co-processed excipients, MicroceLac ${ }^{\circ} 100$ (75\% lactose monohydrate $+25 \%$ microcrystalline cellulose) and StarLac (85\% lactose monohydrate $+15 \%$ white native maize starch) graciously donated by Meggle Wasserburg GmbH \& Co. KG, Germany, were used as reference standards for comparison.

\section{Characterization of the SeDeM parameters of the primary excipients}

A total of thirteen parameters were included in the study (Table 1). These comprise of the CMAs of the excipients characterized using pharmacopoeial methods and standard procedures reported in the relevant literatures. Triplicate determinations were conducted, except otherwise specified.

\section{Densities}

Bulk density $\left(\rho_{b}\right)$ and tap density $\left(\rho_{t}\right)$ were determined according to the procedure (measurement in a graduated cylinder) described in the United States Pharmacopoeia with modifications $[30,31]$. Thus, $\left(\rho_{b}\right)$ was determined by dividing the weight $(w)$ of the sample material by its loose volume $\left(v_{b}\right)$ occupied in a $250( \pm 2) \mathrm{mL}$ measuring cylinder. Tapped density $\left(\rho_{t}\right)$ was determined by subjecting the cylinder to $250-500$ taps on a hard-flat surface until a constant volume $\left(v_{t}\right)$ was attained. The tap density value was obtained as the ratio of $w$ to $\left(v_{t}\right)$.

Table 1 Studied parameters and their theoretical specification limits [28]

\begin{tabular}{|c|c|c|c|c|c|c|}
\hline Incidence & Symbol & Parameter name & Symbol & Unit & $L S L$ & USL \\
\hline \multirow[t]{2}{*}{ Dimension } & $\mathrm{D}$ & Bulk density & $\rho_{b}$ & $\mathrm{~g} / \mathrm{mL}$ & 0 & 1 \\
\hline & & Tapped density & $\rho_{\mathrm{t}}$ & $\mathrm{g} / \mathrm{mL}$ & 0 & 1 \\
\hline \multirow[t]{4}{*}{ Compressibility } & $\psi_{c}$ & Carr's index & Carr & $\%$ & 0 & 50 \\
\hline & & Interparticle porosity & le & - & 0 & 1.2 \\
\hline & & Cohesion index & Icd & $N$ & 0 & 200 \\
\hline & & ${ }^{\mathrm{a}}$ Friability & $\mathrm{Fr}$ & $\%$ & 1 & 0 \\
\hline \multirow[t]{3}{*}{ Flowability } & $\psi_{f}$ & Hausner's ratio & $H R$ & - & 3 & 1 \\
\hline & & Powder flow & t" & $\mathrm{Sec}$ & 0 & 10 \\
\hline & & Angle of repose & Өr & $\circ$ & 50 & 0 \\
\hline \multirow[t]{2}{*}{ Lubricity/stability } & $C_{s}$ & Loss on drying & $\% \mathrm{H}$ & $\%$ & 0 & 10 \\
\hline & & Hygroscopicity & $\% \mathrm{RH}$ & $\%$ & 20 & 0 \\
\hline \multirow[t]{2}{*}{ Lubricity/dosage } & $\phi_{p}$ & Particle size $<75 \mu m$ & $\% \mathrm{Pf}$ & $\%$ & 50 & 0 \\
\hline & & Homogeneity index & $\mid \Theta$ & - & 0 & 0.02 \\
\hline
\end{tabular}

LSL theoretical lower specification limit of parameter, USL theoretical upper specification limit of parameter

${ }^{\text {a }}$ The parameter was not included in the original system 


$$
\begin{aligned}
& \rho_{b}={ }^{w} / v_{b} \\
& \rho_{t}=w / v_{t}
\end{aligned}
$$

\section{Hausner's ratio, Carr's index, and interparticle porosity}

The Hausner's ratio (HR) and Carr's index (IC) were calculated from the bulk and tapped densities using Eqs. 3 and 4, respectively [31].

$$
\begin{aligned}
& H R=\rho_{t} / \rho_{b} \\
& I C=100\left(\frac{\rho_{t}-\rho_{b}}{\rho_{t}}\right)
\end{aligned}
$$

The interparticle porosity Ie was determined as:

$$
I e=\left(\frac{\rho_{t}-\rho_{b}}{\rho_{t} \cdot \rho_{b}}\right)
$$

\section{Angle of repose}

To determine the angle of repose $\left(\theta_{r}\right), 10 \mathrm{~g}$ of powder sample was placed into a cotton-plugged glass funnel suspended vertically on a retort stand such that its tip was 7-cm away from the base of an A4-sized plane sheet. After unblocking the funnel, a powder heap with a height $(h)$ and a diameter $(d)$ was formed on the sheet. $\theta_{r}$ is thus the angle made by the inclined plane of the cone to the base and was derived from Eq. 6 [30].

$$
\theta r=\tan ^{-1}\left(\frac{h^{\prime}}{d^{\prime} 0.5}\right)
$$

where $h^{\prime}$ and $d^{\prime}$ are respectively the means of triplicate measurements of the heights and diameters of the cone measured along different axes.

\section{Powder flow}

Powder flow ( $t$ ") was measured using flowmeter (Erweka, Type GDT, Germany) as the rate at which sample weight $(m)$ is discharged from the funnel compartment [32].

$$
t^{\prime \prime}=m / t
$$

where $t$ is the time for powder discharge.

\section{Loss on drying $(H)$}

Powder sample $\left(w_{i}\right)$ was evenly spread on weighed aluminum foil and dried to a constant weight $\left(w_{f}\right)$ in hot air oven (LabTech, India) at $105 \pm 2^{\circ} \mathrm{C}$ for $3 \mathrm{~h}$. The moisture content $(\% \mathrm{H})$ was calculated as the percentage loss in weight.

$$
\% \mathrm{H}=100\left(\frac{\mathrm{w}_{i}-\mathrm{w}_{f}}{w_{i}}\right)
$$

where $w_{i}$ is the initial weight of sample and $w_{f}$ is the final weight of sample after drying, respectively.

\section{Hygroscopicity (\%RH)}

$\% \mathrm{RH}$ was determined gravimetrically by placing weighed powder sample in the upper compartment of a desiccator containing saturated solution of sodium chloride (RH: 75.5\%) in the lower compartment. The moisture was allowed to equilibrate in the chamber for $24 \mathrm{~h}$, and hygroscopicity calculated as the \% weight of moisture adsorbed by the sample [32-34].

$$
\% R H=100\left(\frac{S_{2}-S_{1}}{S_{1}}\right)
$$

where $S_{1}$ and $S_{2}$ are initial and final weights of the sample, respectively.

\section{Cohesion index}

To determine cohesion index (Icd), powder sample weighing $100 \pm 3 \mathrm{mg}$ was compressed using single-punch tableting machine (Model SSP-12, Shakti Pharmatech PVT. LTD, India) equipped with elongated convex-faced punches $(8 \mathrm{~mm} \times 4 \mathrm{~mm})$ having upper punch scoring. Compression force of $10 \mathrm{KN}$ was applied to form compacts at a production speed of $\sim 100$ tablets $/ \mathrm{min}$. To avoid ejection defects and damages to the punches and die cavity by the poorly compressible corn starch, it was blended with standardized formula of lubricants $(0.5 \%$ magnesium stearate, $0.14 \%$ colloidal silicone dioxide, and $2 \%$ talc) just prior compression [25]. The tablets were stored in moisture-proof desiccator to prevent softening of tablets due to effects of extraneous factors such as humidity. Cohesion index (Icd) was recorded for six compacts as the force required to trigger fracture along the short tablet axis and parallel to the scoring using digital tablet hardness tester (Model THT-2 Biobase, India). To allow for elastic recovery and thus prevent false hardness values, measurements were conducted 24 $\mathrm{h}$ post production [35].

\section{Friability}

Friability $(F r)$ value was determined according to United States Pharmacopoeia. Because the unit weight of the tablets was $100 \mathrm{mg}$, the sample corresponding to $6.5 \mathrm{~g}$ was used in the test. The tablets were placed in the cylinder of a friabilator (Model TFT-3, Biobase Biodustry Co. Ltd, Shandong, China) and set at $25 \mathrm{rpm}$ for $4 \mathrm{~min}$. Fr was calculated according to Eq. 10 [36]. 


$$
F_{r}=100\left(\frac{\mathrm{w}_{1}-\mathrm{w}_{2}}{\mathrm{w}_{1}}\right)
$$

where $w_{1}$ is the initial tablet weight, while $w_{2}$ is the final weight of unfragmented tablets after tumbling. Samples that have shown broken compacts were considered to have failed the test.

\section{Particle size $<75 \mu \mathrm{m}(\% \mathrm{Pf})$ and homogeneity index $(I \Theta)$}

These parameters were obtained by setting $100 \mathrm{~g}( \pm 2 \mathrm{~g})$ of powder sample into $10 \mathrm{~min}$ vibration in a sieve shaker (Ro-Tap ${ }^{\circ}$ Model E, W.S Tyler, Ohio USA). The nest of sieves was arranged in descending order as $420 \mu \mathrm{m}, 300$ $\mu \mathrm{m}, 250 \mu \mathrm{m}, 180 \mu \mathrm{m}, 150 \mu \mathrm{m}, 125 \mu \mathrm{m}, 90 \mu \mathrm{m}$, and 75 $\mu \mathrm{m}$ on a collecting pan. The fraction of powder expressed in percentage that passed through the $75-\mu \mathrm{m}$ sieve was recorded as the $\% P f$. Homogeneity index, $I \theta$ was calculated from Eq. 11 [37].

$$
\mathrm{I} \theta=\frac{\mathrm{F}_{\mathrm{m}}}{100+\left(\mathrm{d}_{\mathrm{m}}-\mathrm{d}_{\mathrm{m}-1}\right) \mathrm{F}_{\mathrm{m}-1}+\left(\mathrm{d}_{\mathrm{m}+1}-\mathrm{d}_{\mathrm{m}}\right) \mathrm{F}_{\mathrm{m}+1}+\left(\mathrm{d}_{\mathrm{m}}-\mathrm{d}_{\mathrm{m}-2}\right) \mathrm{F}_{\mathrm{m}-2}+\left(\mathrm{d}_{\mathrm{m}+2}-\mathrm{d}_{\mathrm{m}}\right) \mathrm{F}_{\mathrm{m}+2}+}
$$

where

$F_{m}$ : Percentage of particles in the majority range

$F_{m-1}$ : Percentage of particles in the range immediately below the majority range

$F_{m+1}$ : Percentage of particles in the range immediately above the majority range

$d_{m}$ : Mean diameter of the particles in the majority fraction

$d_{m-1}$ : Mean diameter of the particles in the fraction of the range immediately below the majority range

$d_{m+1}$ : Mean diameter of the particles in the fraction of the range immediately above the majority range

Setting of parameter limits, transformation of experimental parameter values into radius limits, and construction of SeDeM diagrams

A specified in the literature [28], the acceptable range for each parameter comprises of a lower specification limit (LSL) and an upper specification limit (USL) (Table 1). Equation 12 was used to transform the obtained experimental parameter value $(\bar{y})$ in the range [LSL, USL] into polygon radius value $(r)$ within the range [LRL, $\mathrm{URL}$. For $\bar{y}>\mathrm{USL}$ and $\bar{y}<\mathrm{LSL}$, values were respectively rounded up to the corresponding USL and LSL prior to transformation. Thus, the transformation function for obtaining the polygon radius value for each parameter was given in Eq. 12. The SeDeM diagrams of individual materials were constructed from the transformed $r$ values of the 13 studied parameters using Microsoft Excel Worksheet.

$$
r=\frac{(\overline{\mathrm{y}}-L S L)(U R L-L R L)}{U S L-L S L}+L R L
$$

where

$r$ : Transformed radius value of the parameter

$\bar{y}$ : Parameter value

LSL: Theoretical lower specification limit of the parameter

USL: Theoretical upper specification limit of the parameter

$L R L$ : Lower radius limit $=0$

URL: Upper radius limit $=10$

\section{Calculation of flowability and compressibility functions, lubricity/dosage, and composite stability}

The flowability function, $\psi_{f}$ of the excipients was expressed as the arithmetic mean of radii values of Hausner's ratio $(I H)$ angle of repose $\left(\theta_{r}\right)$, and powder flow $\left(t^{\prime \prime}\right)$. The compressibility function, $\psi_{\mathrm{c}}$ was measured as the arithmetic mean of radii values of interparticle porosity $(I e)$, Carr's index (IC), cohesion index (Icd), and friability (Fr) $[25,37]$.

$$
\begin{aligned}
& \psi_{f}=\left(I H+\theta_{r}+t^{\prime \prime}\right) / 3 \\
& \psi_{c}=(I e+I C+I c d+F r) / 4
\end{aligned}
$$

Lubricity/dosage $\left(\phi_{p}\right)$ was derived as the mean radii of homogeneity index $(I \theta)$ and particle size $<75 \mu \mathrm{m}(\% P f)$. Composite stability was calculated as the mean radii of hygroscopicity $(\% \mathrm{RH})$ and loss on drying $(\% \mathrm{H})[25]$.

$$
\begin{aligned}
& \phi_{p}=(I \Theta+\% P f) / 2 \\
& \complement_{s}=(\% \mathrm{H}+\% \mathrm{RH}) / 2
\end{aligned}
$$

\section{Calculation of parameter index, parametric profile index,} and good compression index (IGC)

Parameter index (IP) was computed by counting the number of parameters (with radii $r \geq 5$ ) and dividing by 13. Parametric profile index (IPP) was obtained as the arithmetic mean of all radii values. Good compression index (IGC) was computed according to Eq. 17 [37, 38].

$$
I G C=\operatorname{IPP}\left(\frac{\mathrm{A}_{13}}{\mathrm{~A}_{\mathrm{c}}}\right)
$$

where $A_{13}$ and $A_{c}$ are the area of a 13-sided regular polygon and area of a circle, respectively. 


$$
\frac{A_{13}}{A_{c}}=\frac{\left(\frac{r^{2} n \sin \left(\frac{360}{n}\right)}{2}\right)}{\pi r^{2}}
$$

where $\frac{A_{13}}{A_{c}}, r$ and $n$ are the reliability constant, circumradius, and number of sides of the polygon, respectively.

\section{Mathematical computation of the amount of corrective excipient (MCC) required to remedy the deficient excipient (corn starch)}

Since corn starch was considered to contribute minimal compressive properties compared to microcrystalline cellulose, the latter was termed as the "corrective" excipient while the former was regarded as the "deficient" excipient. Using the equation proposed by the SeDeM system, in calculation of dilution potential, the amount of MCC required to compensate for low compressibility of corn starch was predicted as [38].

$$
C E=100-\left(\left(\frac{\psi_{c}-R}{\psi_{c}-\psi_{c d}}\right) X 100\right)
$$

where

$C E$ : \% of the corrective excipient

$\psi_{c}$ : Mean compressibility radius value of the corrective excipient

$R$ : Target mean compressibility value $=5$

$\psi_{c d}$ : Mean compressibility radius value of the deficient excipient

\section{Preparation of Starch-MCC composites by co-dispersion}

The calculated amounts of the primary excipients from "Preparation of Starch-MCC composites by codispersion" section were triturated in $500 \mathrm{ml}$ deionized water followed by addition of $2.5 \%$ (w/v) aqueous solution of polyvinylpyrrolidone to strengthen interparticle bonding. Controlled heating was maintained over digital hot plate with internal temperature of the system controlled at $60^{\circ} \mathrm{C}$ for $15 \mathrm{~min}$. The co-dispersed slurry was convectively dried in hot air oven chamber (LabTech, India) for $2 \mathrm{~h}$. The damp mass was screened through $500-\mu \mathrm{m}$ mesh and further dried for $20 \mathrm{~h}$ under same condition. The resulting Starch-MCC composite was size reduced by impact and attrition phenomenon using horizontally mounted ball mill operated at 130 revolution per minute for $20 \mathrm{~min}$ on All Purpose Equipment (AP-01 Plus, Orchid Scientific, India). The resulting coprocessed powder was screened through $250-\mu \mathrm{m}$ sieve size and the product stored in air tight polyvinyl chloride plastic containers until further use [39].
Evaluation of the impact of co-processing on the resulting Starch-MCC composites

The CMAs of the Starch-MCC composites were characterized using the SeDeM methodology. The propensity for direct compaction manufacture of the engineered Starch-microcrystalline cellulose composites in relation to that of commercially available reference co-processed excipients (MicroceLac ${ }^{\circ} 100$ and StarLac ${ }^{\circ}$ ) was evaluated using Flowability Functions, Compressibility Functions, Lubricity/dosage, Composite stability, and Index of Good Compression as previously described.

\section{Results}

Interpretation of SeDeM diagrams and bulk level solid properties of the materials

The SeDeM diagram is a polygonal diagrammatic representation of the multivariate bulk level parameters influencing direct compression manufacturability (Figs. 1, 2, and 3). Each diagram consists of 13-radii interconnecting the center (where $r=0$ ) to the vertices (where $r=10$ ) of the polygon. Thus, the experimentally determined parameter radii values (Table 2) formed a characteristic polygonal shape when presented in the diagram [37], from which formulators could easily understand the weight and hence the desirability of each parameter by the point it occupied along the radius length. The desired minimum acceptable value (MAV) for each parameter is $r \geq 5.0$. The magnitude of the shaded area formed by the radii values when all points were interconnected provided a quantitative description of direct compression functionality of the studied materials.

Co-processing entails screening and optimization of bulk level properties of the parent excipients to obtain composites with enhanced properties [16, 17]. By using the parameter limits of the SeDeM Expert System (Table 1 ), screening procedures of variables with suboptimal values is straight-forward and require no complex statistical computation.

Referring to the SeDeM diagrams of the primary excipients (Fig. 1), a sharp contrast in terms of the material characteristics exists. Corn starch, the poorly compactible excipient, had suboptimal radii values of Carr's index, interparticle porosity (Ie), cohesion index (Icd), friability $(\mathrm{Fr})$, powder flow ( $\left.\mathrm{t}^{\prime \prime}\right)$, angle of repose $(\Theta \mathrm{r})$, and percentage of particles less than $75 \mu \mathrm{m}(\% \mathrm{Pf})$. Microcrystalline cellulose displayed suboptimal values with respect to bulk and tap densities, Ie, Or, and \%Pf. Therefore, the SeDeM diagram was employed as semiqualitative preformulation tool to screen parameters of the primary excipients that require modification to the desired acceptable thresholds using appropriate coprocessing technique.

The SeDeM diagram of the engineered starch-MCC composites indicated better material characteristics than 

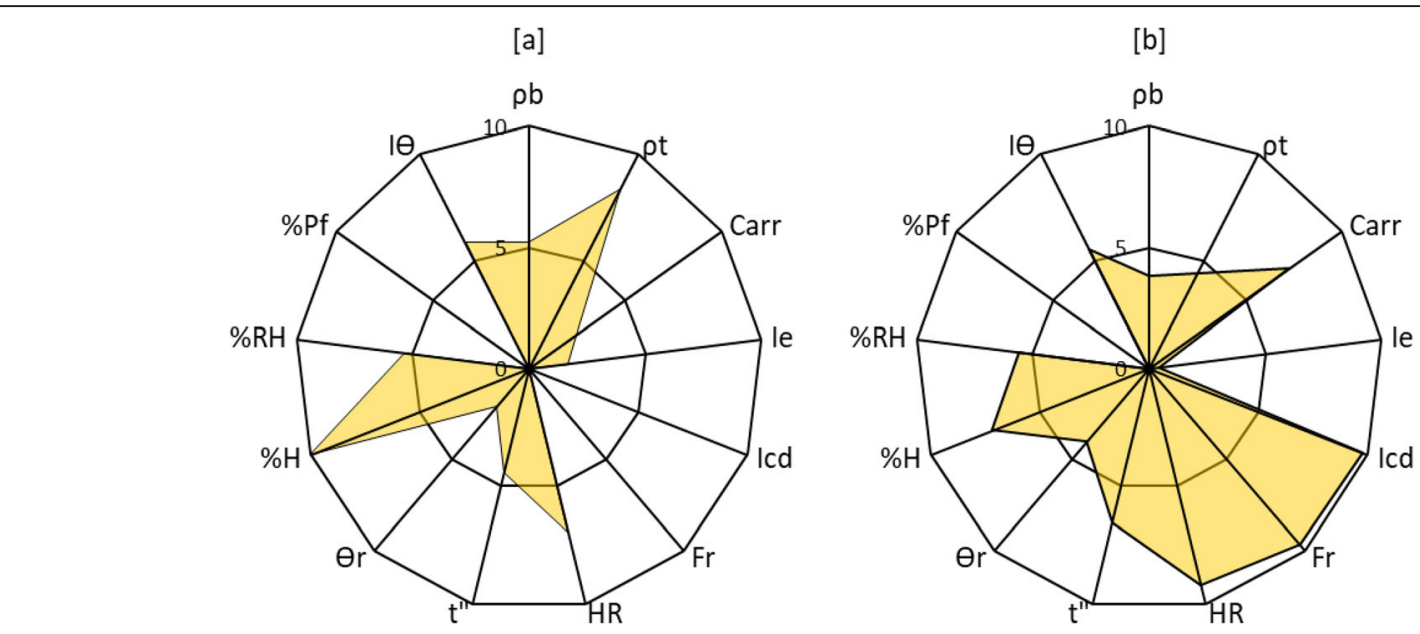

Fig. 1 SeDeM diagrams of corn starch (a) and microcrystalline cellulose (b)

either of the primary excipients. The functional deficiencies of corn starch were masked by microcrystalline cellulose, and the recombinant composite displayed better material characteristics.

\section{Flowability and compressibility functions, parametric profile index, and good compression index}

Flowability $\left(\psi_{\mathrm{f}}\right)$ and compressibility $\left(\psi_{\mathrm{c}}\right)$ functions were measures of fluidity and volume reduction propensities and their MAV is 5.0, each $[25,37]$. These functions constitute critical predictors of direct compression appropriateness of materials [37]. Thus, considering Table 3, corn starch powder was a poor candidate for direct compression. The corrective excipient, microcrystalline cellulose demonstrated better values of the functions.

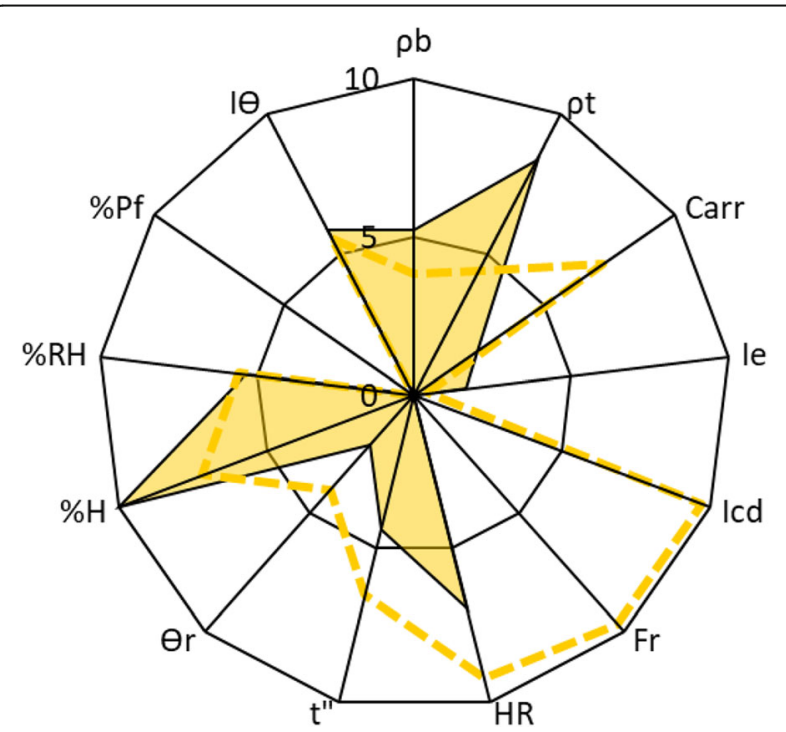

Fig. 2 Superimposed SeDeM diagrams of MCC (dotted lines) and corn starch (shaded area)
The parameter profile (IP) summarized the number of parameters whose polygon radii values were equal to or above the minimum acceptable threshold of 0.5 . This theoretical point requires that up to $50 \%$ of the studied parameters to attain acceptable polygon radii values. Based on our findings, corn starch powder had only $6(46.15 \%)$ acceptable parameter values compared to MCC with 8 (61.55\%). The engineered starch-MCC composite had up to 12 (92.31\%) acceptable parameters which was equivalent to the values for StarLac.

The parametric profile index (IPP) is the average of all the mean radii values and has minimum acceptable value of 5.0. The multiplicative output of the IPP and the reliability constant $\left(\mathrm{A}_{13} / \mathrm{A}_{0}\right)$ in Eq. 17 quantitatively described the IGC which predicted the overall direct compression performance of the materials. It suffices to note that the reliability of SeDeM Expert System and hence its robustness in predicting direct compression suitability depends on the reliability constant, whose numerator expressed the area of an $n$-sided regular polygon ( $n$ studied parameters) relative to the area of a circle (infinite parameters) [26, 37]. An ideal reliability has a value of unity but is seldom attained due to limited number of parameters studied. In our research, thirteen parameters were studied and a reliability constant of 0.961 was obtained indicating better predictive power.

The MAV for the IGC is 5.0, while the optimal theoretical value is 8.23 [37]. Prior to co-processing, corn starch had IGC of only 3.87. After co-processing with MCC, the value increased to 6.46 which was comparable to the experimental compression profiles of StarLac ${ }^{\circ}$ and MicroceLac 100.

\section{Discussion}

Postulating a systematic approach to co-processing of solid directly compressible co-processed excipients using SeDeM Expert System approach

Application of SeDeM Expert System in particle engineering design space of novel co-processed 

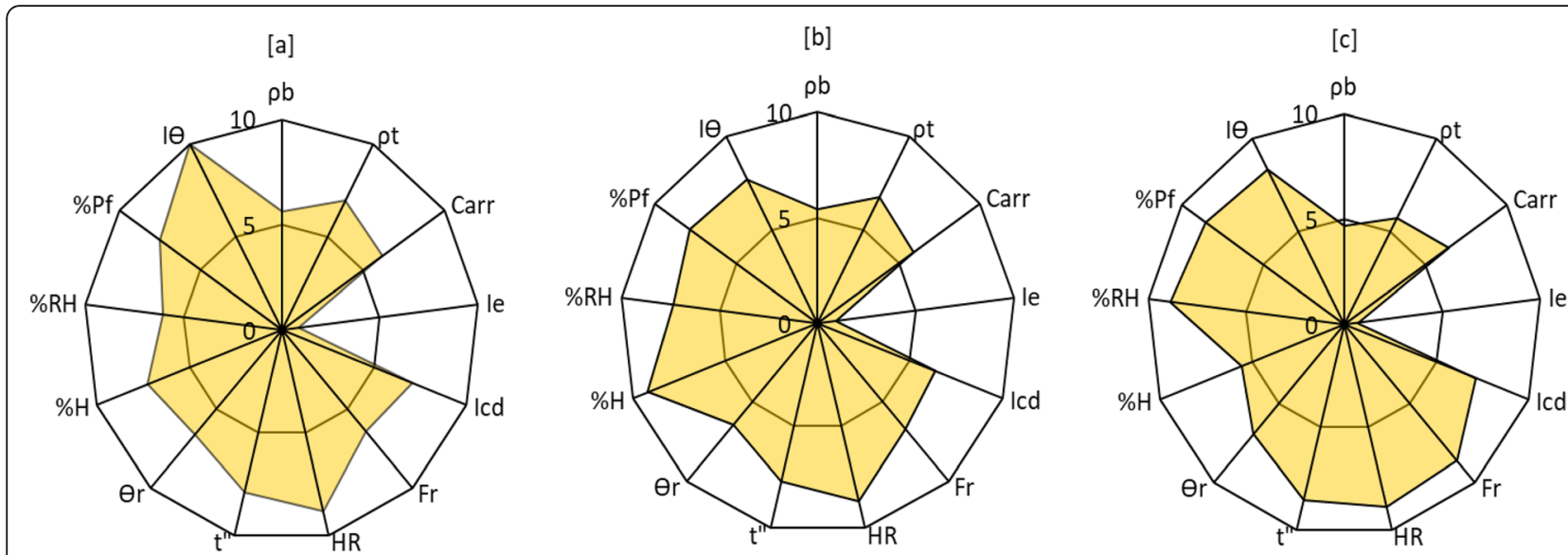

Fig. 3 SeDeM diagrams of engineered Starch-MCC composite (a), StarLac ${ }^{\oplus}(\mathbf{b})$, and MicroceLac ${ }^{\oplus} 100$ (c)

composites provided an upstream proactive mechanism for designing materials with direct compaction propensity in a $\mathrm{QbD}$ fashion. The preformulation information gathered from SeDeM diagrams, IP, IPP, IGC, $\psi_{\mathrm{f}}$, and $\psi_{\mathrm{f}}$ functions provided an avenue for critical understanding of the functionality of the primary excipients useful for systematic design of co-processed excipients. This study therefore postulates a four-stage systematic product design of novel coprocessed excipients as schematically outlined in Fig. 4 and critically discussed below.

\section{Stage I: SeDeM characterization of both defective and corrective materials using SeDeM methodology}

Since co-processing requires critical understanding of bulk-level characteristics of parent excipients enlisted in Table 1 and how their interactions affect the downstream processing as well as quality and functionality of the resulting co-processed composites [29, 30], this stage utilized SeDeM Expert System for preformulation analysis to identify the physicomechanical pros and cons of the primary excipients and elucidate the potential of the corrective excipient to remedy the deficiencies of the defective excipient.

The SeDeM diagram of corn starch indicated gross physicomechanical inadequacies revealed by the suboptimal polygon radii values Carr, Ie, Icd, $F r, t^{\prime \prime}, \Theta_{r}$, and \%Pf (Fig. 1). This predicted that corn starch powder had poor volume reduction propensity, minimal interparticle low mechanical strength, and high percentage of fine particles which are reported rheological limitations of starch in direct compression tableting [40, 41]. Because powder fluidity and compressibility are desired critical functionality requirement for direct compression, [7, 9] the lower values of flowability $\left(\psi_{f}\right)$ and compressibility

Table 2 Mean polygon radii values of the various studied parameters

\begin{tabular}{|c|c|c|c|c|c|c|}
\hline Parameter & Symbol & Corn starch & Microcrystalline cellulose & Starch-MCC composites & StarLac ${ }^{\circledast}$ & Microcelac ${ }^{\oplus} 100$ \\
\hline Bulk density & $\rho_{b}$ & 5.22 & 3.81 & 5.62 & 5.39 & 4.69 \\
\hline Tapped density & $\rho_{t}$ & 8.40 & 4.42 & 6.93 & 6.77 & 5.72 \\
\hline Carr's index & Carr & 2.43 & 7.27 & 6.21 & 5.91 & 6.41 \\
\hline Interparticle porosity & le & 1.65 & 0.43 & 0.88 & 0.92 & 0.70 \\
\hline a Cohesion index & $\mathrm{Icd}$ & 0.00 & 9.74 & 7.09 & 6.36 & 7.15 \\
\hline${ }^{\mathrm{b}}$ Friability & $\mathrm{Fr}$ & 0.00 & 9.69 & 6.44 & 6.73 & 8.60 \\
\hline Hausner's ratio & $H R$ & 6.95 & 9.21 & 8.82 & 8.71 & 8.90 \\
\hline Powder flow & $t^{\prime \prime}$ & 4.39 & 6.52 & 7.91 & 7.72 & 8.59 \\
\hline Angle of repose & Or & 2.11 & 4.01 & 6.61 & 6.43 & 6.94 \\
\hline Loss on drying & $\% \mathrm{H}$ & 10.00 & 7.17 & 7.26 & 9.20 & 5.57 \\
\hline Hygroscopicity & $\% \mathrm{RH}$ & 5.35 & 5.59 & 6.06 & 7.36 & 8.88 \\
\hline Particle size $<75 \mu m$ & $\% \mathrm{Pf}$ & 0.01 & 0.00 & 7.47 & 7.85 & 8.54 \\
\hline Homogeneity index & $1 \Theta$ & 5.87 & 5.57 & 10.00 & 7.73 & 8.30 \\
\hline
\end{tabular}

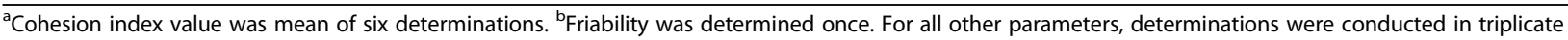


Table 3 Incidence values of the studied excipients

\begin{tabular}{lllllll}
\hline Incidence & Symbol & Corn starch & MCC & Starch-MCC composites & StarLac $^{\oplus}$ & MicroceLac $^{\oplus} 100$ \\
\hline Compressibility function & $\Psi_{c}$ & $1.02^{a} \pm 0.01^{b}$ & $6.78 \pm 0.03$ & $5.16 \pm 0.14$ & $4.98 \pm 0.03$ & $5.72 \pm 0.11$ \\
Flowability function & $\Psi_{f}$ & $4.48 \pm 0.06$ & $6.58 \pm 0.34$ & $7.78 \pm 0.17$ & $7.62 \pm 0.29$ & $8.14 \pm 0.09$ \\
Powder stability & $C_{s}$ & $7.68 \pm 1.25$ & $6.38 \pm 0.22$ & $6.66 \pm 0.85$ & $8.28 \pm 1.30$ & $7.23 \pm 2.34$ \\
Lubricity/dosage & $\phi_{p}$ & $2.94 \pm 0.33$ & $2.78 \pm 0.22$ & $8.74 \pm 0.17$ & $7.79 \pm 0.02$ & $8.42 \pm 0.86$ \\
Parameter profile & IP & 0.46 & 0.62 & 0.92 & 0.92 & 0.85 \\
Parametric profile index & IPP & $4.03 \pm 0.23$ & $5.65 \pm 0.08$ & $6.72 \pm 0.27$ & $6.70 \pm 0.15$ & $6.85 \pm 0.03$ \\
Good compression index & IGC & $3.87 \pm 0.23$ & $5.43 \pm 0.08$ & $6.46 \pm 0.26$ & $6.44 \pm 0.14$ & $6.58 \pm 0.03$ \\
\hline
\end{tabular}

For all parameters $a$ and $b$ are mean and standard deviations of triplicate determinations, respectively

functions $\left(\psi_{c}\right)$ presented in Table 3, predicted the nonsuitability of the corn starch powder in imparting the requisite die filling capacity and the desired tensile strength to furnish tablets of acceptable QTPPs. Based on IP values, only six out of the thirteen parameters of corn starch have passed the MAV. The IGC value further predicted gross physicomechanical inadequacies of corn starch as excipient for direct compression.

Conversely, the SeDeM diagram of MCC powder indicated acceptable values of Carr, Icd, Fr, HR, and $t^{\prime \prime}$ (Fig. 1b), suggesting better volume reduction propensity, excellent dry binding ability, high mechanical strength, and moderate flowability than corn starch powder. This is true of intrinsic properties of MCC because its molecular structure has numerous hydrogen groups on the surface of the cellulose moieties [42], whose spatial proximities conferred a unique ease of formation of numerous hydrogen bonding interactions during compression cycle, even at low compaction pressures making the tablets mechanically stronger $[9,42]$. Despite its compressional advantages over corn starch, MCC was characterized by higher percentages of fine particles $<75 \mu \mathrm{m}$ that explained the low values of $\theta_{r}$ and inferior lubricity/dosage $\left(\phi_{p}\right)$. However, $\psi_{f}$ was equally acceptable because both the $H R$ and $t$ " were within the acceptable threshold. IP values of 0.62 suggested that up to eight of all the parameters studied had acceptable polygon radii values. An IGC of 5.43 indicated overall suitability for direct compression. MCC was therefore selected as a suitable candidate to function as a corrective excipient to improve the compressional deficiencies of corn starch.

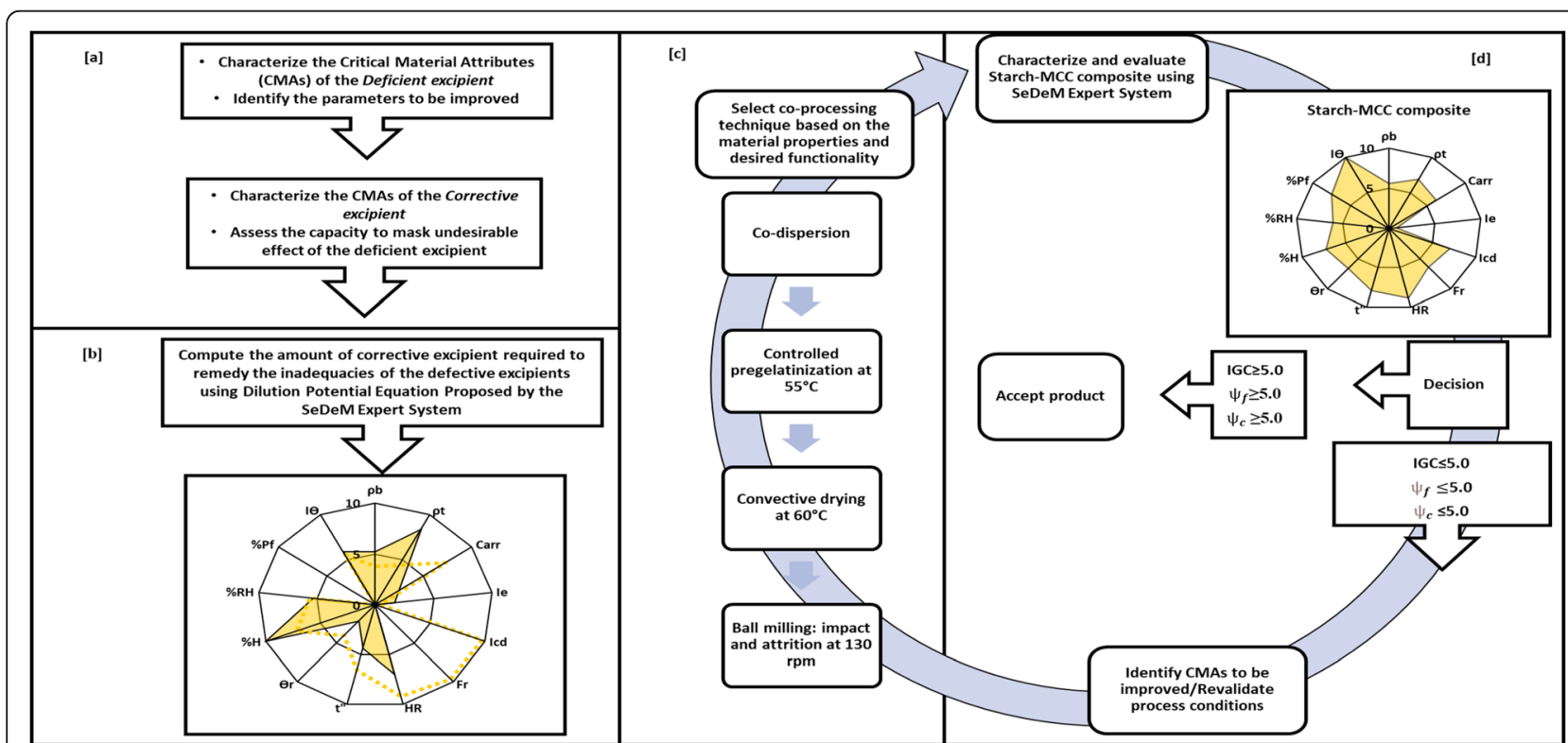

Fig. 4 Application of SeDeM Expert System in particle engineering design space of co-processed excipients. Stage I involves the characterization of Critical Material Attributes (CMAs) of both defective and corrective materials using SeDeM methodology [a]. Stage II: Computing the loading capacity of the corrective excipient using dilution potential equation proposed by the SeDeM Expert System [b]. Stage III: Selection of coprocessing technique based on intrinsic material property and desired CMAs [c]. Stage IV: Evaluating the impact of co-processing by monitoring the critical behavior of the engineered composite with the decision on either to accept or reject the product [d]. Upon failing to meet up with the critical specifications or acceptance criteria, the process conditions in Stage III can be revalidated or modified. IPP: Parametric Profile Index, IGC: Good Compression Index, $\psi_{c}$ : Compressibility function, $\psi_{\mathrm{f}}$ : Flowability function 


\section{Stage II: Computation of the loading capacity of the corrective excipient using dilution potential equation proposed by the SeDeM Expert System}

As an optimization tool, the SeDeM Expert System concept was applied in the determination of the optimum amount of corrective excipient (MCC) required to produce composites of acceptable compression indices in the co-processing stage. This was analogous to the studies on the application of the original system in computing the amount of diluent required to remedy the deficiencies of poorly compactible active ingredients [26, $28,43]$. The superimposed SeDeM diagrams have elucidated the potentials of MCC (dotted lines) to compensate for the lower compressibility indices of corn starch (shaded area) along the Carr, Ie, Icd, and Fr radii sections (Fig. 2). Based on the difference between the compressibility function of MCC $\left(\psi_{\mathrm{c}}\right)$ and that of corn starch $\left(\psi_{\text {cd }}\right)$ optimum co-processing ratio was established according to Eq. 19. Because an optimum percolation threshold is desired to form compacts of acceptable tensile strength [27, 44, 45], computation of the optimum co-processing ratio forms a critical preformulation study to be conducted in the design of co-processed composite. Accordingly, 69 $\%(\sim 70 \%)$ and $30 \%$ amounts of MCC and corn starch powders, respectively, were calculated as the optimum coprocessing ratio.

A practical advantage of this computation approach was that it ruled out the need for conducting series of unnecessary experiments at gradient combination levels of the primary excipient's mixture before optimal combination was obtained; therefore, it was cost-effective and time saving in formulation development of novel excipients.

\section{Stage III: Selection of co-processing technique based on intrinsic material property and the desired CMAs revealed by the information obtained from Stage I}

This stage selects the co-processing technique based on information obtained from Stage $I$ and the desired QTPPs. The sub-optimal radii values of for Carr, Ie, Icd, Fr, $t^{\prime \prime}, \theta_{r}$, and \%Pf for corn starch predicted in Stage I suggested that a co-processing technique that would improve the lubricity dosage, compressibility, and fluidity functions would favorably improve the CMAs of the resulting co-processed composite. A modified co-drying technique involving the sub-stages dispersion, controlled pregelatinization, convective drying, milling, and screening, was employed to achieve this requirement. Controlled pregelatinization was employed to improve compressibility component, while size enlargement aimed to enhance the fluidity function. This was supported by earlier evidence that have shown the impact of pregelatinization on improving material and tableting properties of starches $[40,41]$.
Stage IV: Analysis of the impact of co-processing by monitoring the critical behavior of the engineered StarchMCC composites

This stage applied SeDeM Expert System as a quality control tool to monitor the impact of co-processing conducted in Stage III. It requires SeDeM characterization of the resulting co-processed product as described for the primary excipients followed by critical evaluation of direct compression propensity using the $\psi_{\mathrm{f}}, \psi$, and IGC functions.

After sub-particulate modification of the primary excipients, the SeDeM profile of the engineered StarchMCC composite indicated larger shaded area of the polygon radii values relative to corn starch and MCC powders, implying augmentation of material functionality as a result of co-processing (Fig. 3a).

The lubricity/dosage $\left(\phi_{p}\right)$ consisting of the parameters $\% P f$ and $I \theta$ was included in the SeDeM classification to predict the uniformity of dose in the tablet matrix. Agglomeration of starch granules with MCC particles consolidated by polyvinylpyrrolidone (PVP) solid bridges was responsible for particle size enlargement and substantial reduction of percentage of fine particles in Starch-MCC co-processing [39], and hence, the increased proportion of particles whose dimensions were larger than $75 \mu \mathrm{m}$. Because size enlargement is inversely related to interparticulate friction $[29,30,33]$, the enlarged Starch-MCC composites had reduced interparticulate cohesive and adhesive forces resulting in increased $\theta_{r}$ and $t$ " radii values (Fig. 3a) accounting for the better $\psi_{\mathrm{f}}$ than the corresponding primary excipients (Table 3). On this basis, the powder flow efficiency of the co-processed excipients appeared as MicroceLac $(100>$ Starch-MCC composites $>$ StarLac ${ }^{\circledR}$. Moreover, the impact of co-processing on improving the homogeneity of the compacts was predicted by comparing the $\phi_{p}$ values of corn starch (2.94) and MCC (2.78) to that of Starch-MCC composites (8.74).

Since MCC undergoes extensive plastic deformation even at low compression pressures [39-41], the presence of high percentage of MCC $(70 \% \mathrm{w} / \mathrm{w})$ in the Starch-MCC composite structure outweighed the elastic deformation tendencies due to corn starch $(30 \% \mathrm{w} / \mathrm{w})$ resulting in mechanically stronger compacts with acceptable $I c d$ and Fr. Additionally, the co-processing conditions, mixing temperature of $55^{\circ} \mathrm{C}$ and mechanical agitation for $15 \mathrm{~min}$, were sufficient enough to trigger partial pregelatinization of starch granules which has been reported to improve compressibility of starch [39-41].

Based on the incidence values of Table 3 and the criteria for acceptance of direct compression manufacturability, we can observe that the highest $\psi_{c}$ was exhibited by the pure MCC followed by MicroceLac ${ }^{\oplus}$, Starch-MCC composites, StarLac ${ }^{\oplus}$, and Corn starch, respectively. 
Starch-MCC composite had IP value of 0.92 in comparison to 0.46 and 0.62 for corn starch and MCC, respectively. Based on the IGC values, the suitability of the materials as candidates for direct compression manufacture appeared as MicroceLac ${ }^{\circ} 100>$ Starch-MCC composites $>\mathrm{StarLac}^{\circ}>\mathrm{MCC}$. This implied that the process conditions in the co-processing stage favorably produced composites within the desired parameter ranges and therefore SeDeM Expert System could be regarded as a process control tool for monitoring the impact of coprocessing on material functionality.

\section{Potential limitations}

This study was limited to co-processing of binary powder system of fairly divergent compression physics-elastic deformation for corn starch and plastic deformation for MCC. Because pharmaceutical filler-binders have different physicomechanical functionalities, and that several co-processed excipients comprise of more than two primary excipients, future studies should validate the universality of SeDeM Expert System in co-processing of wide range of raw materials.

\section{Conclusion}

Application of SeDeM Expert System in particle engineering design space of novel co-processed composites provided an upstream proactive mechanism for designing directly compressible co-processed excipients in a QbD fashion. In principle, the system assisted in understanding the critical functionality of the primary excipients enabling a robust science-based approach in the creation of novel excipient via co-processing. It is inferential that integration of computer-based formulation development tools such as SeDeM Expert System could be of significant merit in particle design and optimization of novel directly compressible co-processed excipients.

\footnotetext{
Abbreviations

CMAs: Critical material attributes; CPPs: Critical process parameters; HR: Hausner's ratio; Icd: Cohesion index; ICH: International Council for Harmonization; IGC: Good compression index; IP: Parameter profile; IPP: Parametric profile index; IӨ: Homogeneity index; LRL: Lower radius limit; LSL: Lower specification limit; MAV: Minimum acceptable value; MCC: Microcrystalline cellulose; NCEs: Novel chemical entities; PVP: Polyvinylpyrrolidone; QbD: Quality-by-design; QTPPs: Quality target product profiles; SCEs: Single-component excipients; URL: Upper radius limit; USL: Upper specification limit; $\psi_{\mathrm{c}}$ : Compressibility function;

$\psi_{\mathrm{c}}$ : Compressibility function of defective excipient; $\psi_{\mathrm{f}}$ : Flowability function
}

\section{Authors' contributions}

All authors read and approved the final manuscript.

\section{Declarations}

Competing interests

The authors declare that they have no competing interests.

\section{Author details}

'Department of Pharmaceutics and Pharmaceutical Technology, College of Natural and Pharmaceutical Sciences, Bayero University, PMB 3011, Kano, Nigeria. ${ }^{2}$ Department of Pharmaceutics and Industrial Pharmacy, Ahmadu Bello University, Zaria, Nigeria. ${ }^{3}$ Department of Pharmaceutical Sciences, Università degli Studi di Milano, via G. Colombo, 71, Milano, Italy.

${ }^{4}$ Department of Pharmaceutics and Pharmaceutical Technology, University of Benin, Benin City, Nigeria. ${ }^{5}$ Department of Pharmaceutics and Pharmaceutical Microbiology, Kaduna State University, Kaduna, Nigeria.

Received: 15 February 2021 Accepted: 26 April 2021

Published online: 08 July 2021

\section{References}

1. Novel excipients needed more than ever before. https://www.pharmtech. $\mathrm{com} /$ view/novel-excipients-needed-more-than-ever-before. Accessed 25 Mar 2021

2. Kozarewicz P, Loftsson T (2018) Novel excipients - regulatory challenges and perspectives - The EU insight. Int J Pharm 546:176-179

3. Sieckmann F, Ngoc HN, Helm R, Kohl H (2018) Implementation of lean production systems in small and medium-sized pharmaceutical enterprises. In: Procedia Manufacturing. Elsevier B.V., 21:814-821. https://doi.org/10.1016/ j.promfg.2018.02.188

4. Schweikhart SA, Dembe AE (2009) The applicability of Lean and Six Sigma techniques to clinical and translational research. J Invest Med 57:748-755

5. Nenni ME, Giustiniano L, Pirolo L (2014) Improvement of manufacturing operations through a lean management approach: a case study in the pharmaceutical industry. Int J Eng Bus Manag 6:24. https://doi.org/10.5772/ 59027

6. Armstrong NA (2007) Tablet manufacture by direct compression. Encyclopedia Pharmaceut Technol 6:3673-3683

7. Carlin BAC (2008) Direct compression and the role of filler-binders. In: Augsburger LL, Hoag SW (eds) Pharmaceutical Dosage Forms: Tablets, 3rd edn. New York, Informa, pp 173-246

8. Bolhuis GK, Armstrong NA (2006) Excipients for direct compaction - an update. Pharm Dev Technol 11:111-124

9. Thoorens G, Krier F, Leclerca B, Carlin B, Evrard B (2014) Microcrystalline cellulose, a direct compression binder in a quality by design environment a review. Int J Pharm 473:64-72

10. Mirani AG, Patankar SP, Borole VS, Pawar AS, Kadam VJ (2011) Direct compression high functionality excipient using coprocessing technique: a brief review. Curr Drug Deliv 8:426-435. https://doi.org/10.2174/156720111 795767960

11. Rojas J, Buckner I, Kumar V (2012) Co-processed excipients with enhanced direct compression functionality for improved tableting performance. Drug Dev Ind Pharm 38:1159-1170

12. Saha S, Shahiwala AF (2009) Multifunctional coprocessed excipients for improved tabletting performance. Expert Opin Drug Deliv 6:197-208

13. Preziosi P (2007) Drug Development. In: Comprehensive medicinal chemistry II. Elsevier, pp 173-202. https://doi.org/10.1016/B0-08-045044-X/ 00047-X

14. Nachaegari SK, Bansal AK (2004) Coprocessed Excipients for Solid Dosage Forms. Available via: https://www. pharmtech.com/view/coprocessedexcipients-solid-dosage-forms. Accessed 4 May 2021

15. Mangal S, Meiser F, Morton D, Larson I (2015) Particle engineering of excipients for direct compression: understanding the role of material properties. Curr Pharm Des 21:5877-5889. https://doi.org/10.2174/1381612 821666151008125117

16. Li Z, Lin X, Shen L, Hong YL, Feng Y (2017) Composite particles based on particle engineering for direct compaction. Int J Pharm 519:272-286

17. Apeji YE, Oyi AR, Isah AB, Allagh TS, Modi SR, Bansal AK (2018) Development and optimization of a starch-based co-processed excipient for direct compression using mixture design. AAPS PharmSciTech 19:866-880. https:// doi.org/10.1208/s12249-017-0887-x

18. Pusapati R, Rapeti S, Mvrk K, Murthy T (2014) Development of co-processed excipients in the design and evaluation of atorvastatin calcium tablets by direct compression method. Int J Pharmaceuti Investig 4:102. https://doi. org/10.4103/2230-973x.133059

19. Gohel MC, Jogani PD (2005) A review of co-processed directly compressible excipients 
20. Leuenberger H, Leuenberger MN (2016) Impact of the digital revolution on the future of pharmaceutical formulation science. Eur J Pharm Sci 87:100111. https://doi.org/10.1016/j.ejps.2016.02.005

21. Djekic L, Vasiljevic D, Primorac M (2013) Computer-aided formulation development. In: Computer-aided applications in pharmaceutical technology. Elsevier, pp 17-29. https://doi.org/10.1533/9781908818324.17

22. Deb PK, Al-Attraqchi O, Al-Qattan MN, Raghu Prasad M, Tekade RK (2018) Applications of computers in pharmaceutical product formulation. In: Dosage form design parameters. Elsevier, pp 665-703. https://doi.org/10.101 6/B978-0-12-814421-3.00019-1

23. Kapetanovic IM (2008) Computer-aided drug discovery and development (CADDD): In silico-chemico-biological approach. Chem Biol Interact 171: 165-176. https://doi.org/10.1016/j.cbi.2006.12.006

24. Aguilar JE (2013) Introduction. In: Formulation tools for pharmaceutical development. Elsevier, pp 1-5. https://doi.org/10.1533/9781908818508.1

25. Aguilar-Díaz JE, García-Montoya E, Pérez-Lozano P, Suñé-Negre JM, Miñarro M, Ticó JR (2014) SeDeM Eexpert Ssystem a new innovator tool to develop pharmaceutical forms. Drug Dev Ind Pharm 40:222-236. https://doi.org/1 $0.3109 / 03639045.2012 .756007$

26. Scholtz JC, Steenekamp JH, Hamman JH, Tiedt LR (2017) The SeDeM Expert Diagram System: its performance and predictability in direct compressible formulations containing novel excipients and different types of active ingredients. Powder Technol 312:222-236. https://doi.org/10.1016/j.powtec.2 017.02.019

27. Galdón E, Casas M, Gayango M, Caraballo I (2016) First study of the evolution of the SeDeM Eexpert Ssystem parameters based on percolation theory: monitoring of their critical behavior. Eur J Pharm Biopharm 109:158164. https://doi.org/10.1016/j.ejpb.2016.10.004

28. Suñé Neǵre JM, Roiǵ Carreras M, García RF, Montoya EG, Lozano PP, Aǵuilar JE, Carmona MM, Ticó Grau JR (2013) SeDeM Diagram: an expert system for preformation, characterization and optimization of tablets obtained by direct compression. In: Formulation tools for pharmaceutical development. Elsevier Ltd, pp 109-135. https://doi.org/10.1533/9781908818508.109

29. Moondra S, Maheshwari R, Taneja N, Tekade M, Tekadle RK (2018) Bulk level properties and its role in formulation development and processing. In: Dosage form design parameters. Elsevier, pp 221-256. https://doi.org/10.101 6/B978-0-12-814421-3.00006-3

30. Seville J, Wu C-Y (2016) Bulk solid characterization. In: Particle technology and engineering. Elsevier, pp 17-38. https://doi.org/10.1016/B978-0-08098337-0.00002-3

31. Bulk Density and Tapped Density of Powders / USP (2015) https://www.usp. org/harmonization-standards/pdg/general-chapters/bulk-density-and-ta pped-density-of-powers. Accessed 4 May 2021

32. Newman AW, Muller RL, Vitez IM (2007) Starch and starch derivatives. Encyclopedia Pharmaceut Technol 5:3476-3481

33. Howard SA (2007) Solids: flow properties. Encyclopedia Pharmaceut Technol 6:3275-3296

34. Goh HP, Heng PWS, Liew CV (2018) Comparative evaluation of powder flow parameters with reference to particle size and shape. Int J Pharm 547:133141. https://doi.org/10.1016/j.ijpharm.2018.05.059

35. Mohammed H, Briscoe BJ, Pitt KG (2005) The interrelationship between the compaction behaviour and the mechanical strength of pure pharmaceutical tablets. In: Chemical Engineering Science, Elsevier, Pergamon, pp 39413947. https://doi.org/10.1016/j.ces.2005.02.027

36. Tablet Friability | USP. https://www.usp.org/harmonization-standards/pdg/ general-chapters/tablet-friability. Accessed 29 Mar 2021

37. Suñé-Negre JM, Roig M, Fuster $R$, Hernández C, Ruhí R, García-Montoya $E$, Pérez-Lozano P, Miñarro M, Ticó JR (2014) New classification of directly compressible (DC) excipients in function of the SeDeM Diagram Expert System. Int J Pharm 470:15-27. https://doi.org/10.1016/j.jpharm.2014.04.068

38. Suñé-Negre JM, Pérez-Lozano $P$, Miñarro M, Roig M, Fuster R, Hernández C, Ruhí R, García-Montoya E, Ticó JR (2008) Application of the SeDeM Diagram and a new mathematical equation in the design of direct compression tablet formulation. Eur J Pharm Biopharm 69:1029-1039. https://doi.org/10.1 016/j.ejpb.2008.01.020

39. Salim I, Kehinde OA, Abdulsamad A, Khalid GM, Gwarzo MS (2018) Physicomechanical behaviour of novel directly compressible Starch-MCCPovidone composites and their application in ascorbic acid tablet formulation. Br J Pharm 3. https://doi.org/10.5920/bjpharm.2018.03
40. Odeku OA, Schmid W, Picker-Freyer KM (2008) Material and tablet properties of pregelatinized (thermally modified) Dioscorea starches. Eur J Pharm Biopharm 70:357-371. https://doi.org/10.1016/j.ejpb.2008.04.011

41. Lawal M v. (2019) Modified starches as direct compression excipients effect of physical and chemical modifications on tablet properties: a review. Starch - Stärke 71:1800040. https://doi.org/10.1002/star.201800040

42. Holtzapple MT (2003) Cellulose. In: Encyclopedia of food sciences and nutrition. Elsevier, pp 998-1007. https://doi.org/10.1016/B0-12-227055-X/001 85-1

43. Khan A, Iqbal Z, Rehman Z, Nasir F, Khan A, Ismail M, Roohullah MA (2014) Application of SeDeM Expert Ssystem in formulation development of effervescent tablets by direct compression. Saudi Pharmaceut J 22:433-444. https://doi.org/10.1016/j.jsps.2013.07.002

44. Imbert C, Tchoreloff $P$, Leclerc B, Couarraze G (1997) Indices of tableting performance and application of percolation theory to powder compaction. Eur J Pharm Biopharm 44:273-282. https://doi.org/10.1016/S0939-6411 (97)00134-3

45. Leuenberger $\mathrm{H}$ (1999) Application of percolation theory in powder technology. Adv Powder Technol 10:323-352

\section{Publisher's Note}

Springer Nature remains neutral with regard to jurisdictional claims in published maps and institutional affiliations.

\section{Submit your manuscript to a SpringerOpen ${ }^{\circ}$ journal and benefit from:}

- Convenient online submission

- Rigorous peer review

- Open access: articles freely available online

- High visibility within the field

- Retaining the copyright to your article

Submit your next manuscript at $>$ springeropen.com 